\title{
Relational autonomy: lessons from COVID-19 and twentieth-century philosophy
}

\author{
Carlos Gómez-Vírseda ${ }^{1}$ (1) Rafael Amo Usanos ${ }^{2}$ (이
}

Accepted: 21 June 2021 / Published online: 26 June 2021

(c) The Author(s), under exclusive licence to Springer Nature B.V. 2021

\begin{abstract}
COVID-19 has turned many ethical principles and presuppositions upside down. More precisely, the principle of respect for autonomy has been shown to be ill suited to face the ethical challenges posed by the current health crisis. Individual wishes and choices have been subordinated to public interests. Patients have received trial therapies under extraordinary procedures of informed consent. The principle of respect for autonomy, at least in its mainstream interpretation, has been particularly questioned during this pandemic. Further reflection on the nature and value of autonomy is urgently needed. Relational autonomy has been proposed as an alternative account of autonomy that can more adequately respond to contemporary ethical issues in general and to a pandemic such as the one we are currently facing in particular. As relational autonomy is an emerging notion in current bioethics, it requires further consideration and development to be properly operationalized. This paper aims to show how six different philosophical branches-namely, philosophy of nature, philosophical anthropology, existential phenomenology, discourse ethics, hermeneutics, and cultural anthropology-have incorporated the category of relation throughout the twentieth century. We first delve into primary philosophical sources and then apply their insights to the specific field of medical ethics. Learning from the historical developments of other philosophical fields may provide illumination that will enable bioethics to experience a successful "relational turn", which has been partially initiated in contemporary bioethics but not yet achieved.
\end{abstract}

Keywords COVID-19 · Relational autonomy $\cdot$ Shared decision-making $\cdot$ Global ethics $\cdot$ History of philosophy

\section{Introduction}

Respect for autonomy has been a key principle in bioethics in recent decades (Dworkin 1988; Childress 1990). Nevertheless, many voices have criticized an individualistic approach to this notion, shaped by the American principlism of Beauchamp and Childress (Clouser and Gert 1990; O'Neill 2002; Traphagan 2013). In this regard, the current health crisis caused by COVID-19 may further expose the limits of a narrow interpretation of respect for autonomy $^{1}$ as it is generally understood in the bioethical debate.

Carlos Gómez-Vírseda

carlos.gomezvirseda@kuleuven.be

Rafael Amo Usanos

rafael.amo@comillas.edu

1 Centre for Biomedical Ethics and Law, KU Leuven, Kapucijnenvoer 35/3, 3000 Louvain, Belgium

2 Bioethics Chair at the Universidad Pontificia Comillas, C/Universidad Comillas, 3, 28049 Madrid, Spain
Some authors call for a "relational turn" of this principle that will better respond to the ethical challenges posed by health emergencies such as the COVID-19 pandemic (Jeffrey 2020; Lang and Micah Hester 2021). Along these lines, relational autonomy, an emerging concept in bioethics, is often proposed as an alternative to the individualistic vision of autonomy (Mackenzie and Stoljar 2000). However, a systematic review of this notion has revealed insufficient theoretical and practical development (Gómez-Vírseda et al. 2019). Despite being a potentially promising concept, relational autonomy is far from being clearly conceptualized or

\footnotetext{
1 Throughout this work, we refer to a "narrow interpretation of respect for autonomy" or to "the mainstream view of respect for autonomy" shaped by Anglo-American individualism and liberalism. We acknowledge that there is no single homogeneous account of the principle of respect for autonomy in the current bioethics literature. However, we use this terminology since many authors refer to these or similar notions, often to criticize them. In the cited bibliography, see Mackenzie and Stoljar (2000), Donchin (2001), Rigaux (2011), etc.
} 
practically operationalized. An analysis of the philosophical roots of this deficiency is therefore needed.

In this paper, we aim to respond to this challenge by using a hypothetical-deductive method. Our hypothesis is that medical ethics has not definitively incorporated the concept of relationships into the core of the decision-making process. To achieve successful incorporation, we proceed in four steps. First, we present challenges to the mainstream individualistic view of autonomy, as depicted in recent bioethics literature and confirmed by the current health situation of COVID-19. Second, we expose how the current proposal of relational autonomy fails to provide a satisfactory answer to this problem, due mainly to a weak account of relationality. Third, we analyze six different philosophical branches that successfully integrated the category of relation into their theoretical core during the twentieth century. Fourth, we extract six key insights from this historical analysis that can specifically contribute to bioethics.

We conclude that the category of relation should be integrated into the heart of bioethical theory, transforming the principle of autonomy and thus achieving a better balance between the classical principles of Beauchamp and Childress (2019). This transformation could be particularly helpful in emergency health situations such as COVID-19.

\section{Challenges to individual autonomy}

Respect for autonomy is undoubtedly a key achievement of contemporary bioethics. This concept is behind well-established medico-legal practices such as the use of informed consent or the end of nonvoluntary participation in medical research (Faden and Beauchamp 1986). However, many voices from both ethical theories and clinical practice have criticized a narrow interpretation of this principle.

\section{Challenges from bioethics literature}

Among these dissenting voices, relational authors criticize the mainstream interpretation of the principle of respect for autonomy as excessively shaped by a masculine and Western view of the human person (Mackenzie and Stoljar 2000; Stoljar 2018). Mackenzie and Stoljar (2000) summarize their critiques in five clusters: symbolic, metaphysical, care, postmodernist, and diversity. Rather than rejecting the principle of autonomy altogether, these critiques demand a richer account of the notion that pays "attention to the rich and complex social and historical contexts in which agents are embedded" (Mackenzie and Stoljar 2000, p. 21).

Similarly, a systematic review focused on the use of relational autonomy in end-of-life care detects four criticisms of an individualistic account of autonomy: first, a misconception of the individual self as atomistic, independent, self-transparent, and self-interested; second, an inadequate portrayal of decision-making processes that fails to incorporate the social context and the relational environment; third, a discriminatory prejudice against disabled persons and cultural minorities; and fourth, a cognitive bias in legal documents and health policies (Gómez-Vírseda et al. 2019). These challenges to individual autonomy are detected in recent bioethical literature from eight different ethical approaches, namely, feminism, communitarianism, personalism, care ethics, multiculturalism, phenomenology, relational ethics, and virtue ethics (Gómez-Vírseda et al. 2019).

\section{Challenges from the clinical reality of COVID-19}

Criticisms of an individualistic account of autonomy do not come only from theoretical stances. Clinical reality often challenges an individualistic view of the patient's autonomy. Patients live not "in a cocoon" but in a relational, social and cultural environment that conditions and limits their decisions. This fact has been particularly evident during the COVID-19 crisis.

Along these lines, Jeffrey (2020) identifies three areas of ethical issues that COVID-19 has posed to patients, family members, healthcare professionals, policy makers and the general public: (1) quarantine, isolation and social distancing, which impose limits on individual freedom; (2) healthcare workers' duty to provide care to patients even at their own risk or the risk to their loved ones; and (3) access to treatment when resources are limited. Additionally, the exceptional circumstances caused by COVID-19 have required several organizations to loosen their ethico-legal standards for testing new drugs and treatments (Agencia Española de Medicamentos y Productos Sanitarios 2020; European Medicines Agency 2020; U.S. Department of Health and Human Services Food and Drug Administration 2020). In the midst of an emergency situation, medical research may have taken license to satisfy social needs, in contrast to the usual framework in which the protection of the individual is the highest priority (van der Graaf et al. 2020).

Baum and Żok (2020) argue that maximal individualism-a "prevalent trend" in line with most normative and legal acts-has raised numerous ethical, social, and economic dilemmas in the time of COVID-19. According to these authors, emergency situations require extraordinary ethical standards that regular moral codes do not consider. Hence, respect for autonomy is overridden by other principles, such as "maximizing the common good" and "value to society". A similar concern is expressed by the Hastings Center Ethical Framework (Berlinger et al. 2020), which detects a shift from patient-centered practice to patient care guided by public health considerations. This change is creating great tension among clinicians, policy makers, and the general public since Western societies are not used to working in emergency conditions with scarce resources. 
Calvo et al. (2020) warn about the threat to privacy and individual autonomy from new health surveillance technologies that have been used to identify those who are potentially infected, trace their contacts, and reinforce social distancing. Regarding the dramatic situation of clinical triage, McCullough (2020) argues that the ethical principles of respect for autonomy and patients' preferences should be "irrelevant to evidence-based, beneficence-based deliberative clinical judgment". The exclusion of autonomy-based considerations from the fair application of clinical criteria means that the informed consent process is not required under certain circumstances (McCullough 2020). According to McCullough, clinicians' unilateral authority-not paternalism - may override individual autonomy to prevent harm to other patients by irresponsibly managing unacceptable opportunity costs.

In sum, COVID-19 may have caused a violation of human rights and freedoms due to the urgency of public health measures (Spadaro 2020). It has also strongly affected respect for autonomy, one of the key principles of current bioethics (Jeffrey 2020). We propose that an individualistic view of autonomy is more vulnerable to this reality, and a relational account of autonomy may therefore be more responsive to the challenges posed by the pandemic.

\section{Relational autonomy: still an inadequate alternative}

As stated, the individualistic interpretation of the principle of respect for autonomy has been challenged both from theoretical perspectives and from the clinical reality of COVID-19. A relational approach to this principle is often proposed as a suitable response to these challenges (Jeffrey 2020; Lang and Micah Hester 2021). Although attempts at such a "relational turn" have been made in the specific field of bioethics (Jennings 2016; Sherwin and Stockdale 2017), a systematic review of the notion of relational autonomy detects important deficiencies in these attempts (GómezVírseda et al. 2019). First, relational conceptualizations of autonomy tend to be a reaction against an individualistic interpretation of this principle rather than positive concepts in themselves. Second, as a rich and multisourced concept, relational autonomy generally refers to a single source of inspiration and presents a simplistic, one-sided interpretation. Third, there is a significant distance between theoretical approaches to relational autonomy and their operationalization in end-of-life practices. Thus, relational autonomy proposals have not been able to offer a convincing alternative to the individualistic model of autonomy.

To explain this shortcoming, we suggest that relationality has not been adequately integrated into medical ethics. Our hypothesis is that most relational authors have created a weak account rather than a strong account of relationality. ${ }^{2}$ How can a strong incorporation be achieved? We propose a historical analysis of how different branches of twentiethcentury philosophy successfully integrated relationality into their theoretical core. By learning from these developments, we obtain some useful implications for medical ethics. By doing so, we aim to transform respect for autonomy into a relational principle.

\section{From the history of philosophy to the bioethical implications}

Twentieth-century philosophy played a critical role in the category of relation. A study of six prominent contemporary branches allows us to discover important dimensions of this category. Furthermore, these dimensions are used to advance towards a strong account of relationality in bioethics and, more specifically, the principle of autonomy. However, before examining these tendencies, it is worth briefly reviewing the category of relation in philosophy prior to the contemporary era.

Relation has a long and complex trajectory in philosophical history. Its origin dates back to Aristotle, who calls it "prós ti" since he has no abstract noun to designate it. According to Aristotle, relation is an accident, a category that considers a thing in reference to another. Nevertheless, "[relative terms] belong to the least substantial of all the categories and are posterior to quality and quantity" (Aristotle 1956, p. 281).

Prompted by theological interests, Saint Augustine returns to the category of relation and assigns it a special status (Augustine 417/1956, pp. 401-402). If there is relation in God, he points out, it cannot be a simple accident since God does not have accidents. Furthermore, it cannot be part of the essence since the essence of God is unity. Saint Augustine thus inaugurates a new way of conceiving ontology in which the relative is not accidental but given in substance (Arias 1989, p. 264). In this way, he introduces relationality in the substance, although the substance is not relation itself.

Later works on the category of relation by Thomas Aquinas, Francisco Suárez, and other scholastics triggered more systematic reflection. Generally, relation has been defined by scholasticism as "the ordination or reference that one being has to another" (Valverde 2009, p. 955). To understand

\footnotetext{
2 We adopt the distinction between strong and weak autonomy used by relational authors such as Donchin (2000). This distinction echoes the discussion of constitutive versus causal in contemporary ethics (Westlund 2009). We will show that this tension can be traced throughout the history of philosophy with different nuances and formulations.
} 
the implications of such a definition, one must distinguish between three elements: the first two are the subject and the term of relation, which are both conditio sine qua non, and the third is the foundation, which is the true essence of the relation, the reason why the subject is in relation with its term. Regarding the foundation, there is a triple classification of relation: relation of reason, predicamental relation, and transcendental relation. Only the last two had a true impact on the twentieth-century philosophy to be presented henceforth.

The predicamental relation is the one "which is not essential to the subject but is in the subject in an accidental and contingent way" (Valverde 2009, p. 958). In other words, the predicamental is the relation between a substance and its accident. On the other hand, the transcendental relation "is essential to the subject and, therefore, fully identified with it" (Valverde 2009, p. 958). Thus, the transcendental relation is founded in the very essence of the subject. Therefore, the subject is as it is, and even exists, because its essence is relation.

Kant introduces a new understanding of relation in the sense that twentieth-century philosophers follow. In his Critique of Pure Reason, in discussion of the Transcendental Dialectic, relation falls within the third class of categories of understanding (Kant 1922). Specifically, relations are a priori categories of understanding with which the phenomenon is constructed. Thus, for Kant, relation becomes the soul of all judgment, a universal instrument of knowledge at the expense of substance (Álvarez 1967, p. 341). Through the category of relation, some of the synthetic judgments a priori are produced, namely, categorical, hypothetical and disjunctive judgments, which are the objects of scientific knowledge. In other words, Kant places relation as the very essence of knowledge, which goes beyond the mere predicate, yet without considering it in the transcendental sense with which scholasticism defined it. For Kant, the category of relation enters epistemology; later, this category would make its way into other branches of philosophical knowledge.

Thus, the category of relation followed a path throughout the twentieth century that brought it to the heart of reality itself, whether in terms of nature or the human person. We will now consider six salient philosophical branches that have delved into this category. Those branches will be chronologically presented around two dominant movements that span twentieth-century philosophy, namely, the emergence of social sciences and the evolution of phenomenology. Regarding the former, the category of relation is of the utmost importance to the emergence of social sciences. Within this movement, we present the philosophical branches of cultural anthropology, philosophy of nature, and discourse ethics. Regarding the latter, the evolution of phenomenology occurred throughout the twentieth century, leaving traces on the incipient branches of philosophical anthropology, existential phenomenology and hermeneutics, in all of which the category of relation is also crucial. In due course, we will present certain bioethical implications for the bioethical principle of autonomy extracted from each branch.

\section{Cultural anthropology: relation in the definition of the human}

The objective sense of the concept of culture has taken centuries to crystallize. Even though its origins can be traced back to Cicero, it was the seventeenth-century philosopher von Pufendorf who paved the way for the modern concept of culture as the opposite of a natural state. The colonization of Africa and the philosophical speculations of the Enlightenment prompted a large amount of empirical research of an ethnological nature, giving rise to the comparative study of culture.

Thus, culture was defined in the objective sense. It is first found in Edward Burnett Tylor's work, a clear example of the nineteenth-century evolutionist movement: "Culture or Civilization, taken in the wide ethnographic sense, is that complex whole which knowledge, belief, art, morals, law, custom, and any other capabilities and habits acquired by man as a member of society" (Tylor 1871, p. 1). San Martín, commenting on the elements of culture in this definition, states, "I think that Tylor is referring here to opinions about things, mainly those things that are related to ultimate realities of life, to the meaning of life and society, to the origin and goal of life, to the time before birth and after death and, finally, to the foundation of rights" (Sala 1999, p. 44). In other words, culture somehow conditions our understanding of the world, of ourselves, and of the values shared by human beings.

Thus, in cultural anthropology, the concept of the human being is eminently relational. The biocultural human being is "in relation". From society, the cultural subject receives "the deposit of obvious things that are shared, and not just banal ones, but those that define good and bad, convenient and inconvenient; therefore, those who regulate behaviour" (Amengual 2007, p. 358). Everything that one can think, feel or value is determined largely by culture through the essential relationships with society and with others.

\section{Bioethical implications}

Cultural anthropology demonstrated that human persons are relational beings who receive much of what they are through dynamic interaction with society and culture. Hence, they are historical, concrete, contextual beings. Along these lines, relational authors criticize an abstract conception of the bioethical subject as if operating in a historical and cultural 
vacuum (Donchin 2000; Mackenzie and Stoljar 2000). Nevertheless, studies show that health decisions are indeed strongly shaped by culture (Gilbar and Miola 2015), and not all cultures give the same weight to individual autonomy in decision making (Frosch and Kaplan 1999). Collectivist cultures preferentially consider other values, such as mutual trust, family harmony, filial piety or community fidelity (Gómez-Vírseda et al. 2019). Greater cultural awareness may have important consequences for the management of decision-making processes in clinical settings. Such awareness may require cultural adaptation of communication standards, informed consent procedures, and advance directives. Such a broad perspective demands greater cultural competency among clinicians, enabling them to offer alternatives within the cultural framework of the patient (Betancourt 2004; Fox 2005). In Western culture, the decision-making unit may be the individual, while in other cultures, it is the family, ethnic group, or society (Candib 2002; Gilbar and Miola 2015).

The influence of culture should not be overlooked, even in public health policies. For example, McCullough explains the triage practice in the emergency situation posed by COVID-19 not on a communitarian basis but on a purely liberal one. He rejects the need to resort to arguments centered on society or on the collective; however, he defends triage as an exercise of scientific rationality based on evidence and patient-centered interest (McCullough 2020). Let this serve as a particular example of addressing the individual-society dialectic within a liberal understanding framework. In a different framework, the Hastings Center sees the need to break with the common schemes that govern ethical actions (Berlinger et al. 2020) and therefore supports the need for new ethical foundations, particularly of a communitarian nature, that are justified by the extraordinary situation of the pandemic.

\section{Philosophy of nature: relation in the cosmological understanding}

Collingwood (1945) asserts that since the end of the eighteenth century, a change in the idea of nature has taken place, replacing the mechanistic concept that was dominant until that time. From then on, the explanatory model of nature would be social sciences: just as evolution and process exist in society, so they do in nature. This shift gave rise to an evolutionary view, and henceforth, "nature will be understood as consisting of process" (Collingwood 1945, p. 17). Nature as a process contrasts with the old objectifying vision of substance and would be the gateway of relation into the heart of nature.

A paramount example of this new philosophy of nature appears in Whitehead's work, which introduces dynamism and relation into the definition of being. Whitehead, supported by the physical knowledge of his time, first considers nature-and the matter that composes it-holistically (Whitehead 1938, p. 184, 1964, p. 26). Second, he applies Heraclitus' principle; i.e., "all things flow". This double starting point leads him to introduce the process-which is his name for relation-into the concepts of matter and of being — which he calls an actual entity (Whitehead 1985, p. 41; Ezcurra 1991, p. 72).

The articulation of this double starting point is accomplished through the concept of organism: "The notion of 'organism' is combined with that of 'process' in a twofold manner. The community of actual things is an organism, but it is not a static organism. [...] Secondly, each actual entity is itself only describable as an organic process. It repeats in microcosm what the universe is in macrocosm" (Whitehead 1985, pp. 214-215).

Thus, the category of relation finds a place in Whitehead's philosophy of nature. The return to "organicism" means that everything in the universe is actually related. All macroscopic and microscopic elements are related as parts of an organism, and any causality that occurs in them needs relation as well.

\section{Bioethical implications}

The philosophy of nature, by bringing the category of relation into the core of nature itself, introduces a dynamic vision of matter and concludes that everything is related. The confluence of this idea with parallel claims from environmental sciences (Coutts and Hahn 2015), social sciences (Heilbron 2014) and theology (Marx 2016) is remarkable. Along these lines, COVID-19 has confirmed that health problems can no longer be considered an area exclusive to clinicians. There is a need for effective coordination among various disciplines, such as clinical medicine, public health, ecology, biology, epidemiology, veterinary science, and social and political sciences (Tatay 2020). Each of these disciplines addresses the topic on the basis of its own epistemology, objectives, and methods.

This "cosmological dimension" of relationality has implications for applied ethics. It entails that, in ethical deliberation, human beings are inevitably connected with every other aspect of nature. This connectedness links medical ethics to other ethical fields, such as environmental and global ethics. Tatay (2020), for instance, considers global bioethics a synthesis of medical ethics, public health ethics and environmental ethics. He warns that when this perspective is taken into account, both the anthropocentric approach to biomedicine and the biocentric approach to public health are insufficient to address global problems of a complex nature, such as emerging infectious diseases. Similarly, the WHO project entitled "One Health" proposes a multisectoral approach to public health (Zinsstag et al. 2020) with the aim of "designing 
and implementing programmes, policies, legislation and research in which multiple sectors communicate and work together to achieve better public health outcomes" (WHO 2017).

\section{Discourse ethics: relation as a condition of universal morality}

After the Second World War, universalist reason as the foundation of ethics lost its privileged status. The Frankfurt school displayed pessimism towards reason, while some heirs of critical theory, such as Habermas and Apel, seeking closeness to social sciences and language, attempted to recover the Kantian idea of universal morality. However, they did so by transforming key elements of the Cartesian tradition: "The discursive ethics of Habermas and Apel rejects the privileges given to the solitary moral conscience and opens moral philosophy to all forms of socially regulated interaction. Discursive ethics hold that only a reasoned agreement of those affected by a normative system can make valid such a system. They add that this requires communicative forms of action, not only instrumental or strategic" (Thiebaut 2000, p. 281).

Indeed, Habermas's starting point is a review of the universality of reason. For discourse ethics, reason has a dialogical character. It is a "dialogical logos" (Rueda 2001, p. 371): "the author [Habermas] considers the "dialogical' structure as a constituent a priori of all discernment and knowledge and, therefore, the only solid base on which it is possible to establish a rational approach" (Boladeras 1996, p. 90). This is the so-called (D)-principle, formulated as follows: "Only those norms can claim to be valid that meet (or could meet) with the approval of all affected in their capacity as participants in a practical discourse" (Habermas 1990, p. 93) This dialogical a priori, which could also be called relational a priori, is the great difference from ethics of Cartesian (or even utilitarian) origin, which presupposes an individualistic, selfsufficient, and self-interested subject (Boladeras 1996, p. 91). From the (D)-principle, one can derive the (U)principle: "For a norm to be valid, the consequences and side effects that its general observance can be expected to have for the satisfaction of the particular interests of each person affected must be such that all affected can accept them freely" (Habermas 1990, p. 120).

Both the (D)- and the (U)-principle presuppose the relational structure of human beings since for both, human beings participate dialogically in the elaboration of ethical norms. If they were not based on the category of relation, they could not affirm the decisive role of participatory ethics in practical discourse.

\section{Bioethical implications}

Habermas and Apel bring to the fore the dialogical reason of the relational subject. They hold that human persons achieve universal ethical norms, even for themselves, not individually but through dialogue with others. From this derives the need for relations with others in the search for a shared truth that can guide our actions. A strong current in medical ethics follows this line of reasoning, namely, the shared decisionmaking (SDM) approach. Some scholars have shown that the foundations of SDM lie in discourse ethics ideas (Kon 2010; Müller-Engelmann et al. 2011; Stiggelbout et al. 2015).

SDM includes various practices and procedures that aim to facilitate dialogue between patients, health professionals and patients' families to achieve a consensual form of decision making (Elwyn et al. 2012). SDM is supported by evidence showing knowledge gain by patients, more confidence in decisions, more active patient involvement, and more conservative treatment options in critical situations (Stacey et al. 2017).

Furthermore, dialogic ethics is very sensitive to giving due consideration to the most vulnerable interlocutors (Légaré and Witteman 2013; Mead et al. 2013). In the current health crisis, there is a risk of undermining the dignity of vulnerable patients, such as those who are elderly or disabled, for the sake of supposed social utility (Baum and Żok 2020). Dialogical ethics seeks to give voice to all stakeholders while promoting the protection of the most vulnerable individuals so that the majority does not impose its predominant vision in an authoritarian manner.

\section{The twentieth-century anthropological turn: relation in the human definition}

Various theoretical developments at the end of the nineteenth century challenged the idea of human singularity, including the theory of evolution, which disputed the distance of humans from animals, and Freud's psychoanalysis, which questioned the rationality of human singularity. These developments occurred in the midst of the great cultural breakdown that led to the First World War. This social and cultural environment made the "question of humankind" resurface from different standpoints, giving birth to philosophical anthropology.

Although Kant first introduced the category of relation into epistemology, it was Max Scheler who definitely overcame the anthropological consequences of Descartes's solitary reason (Entralgo 1961, p. 216). Some characteristics of this concept of solitary reason, also called the bourgeois soul, deserve to be mentioned: (1) it was built on the subjectobject dialectic, with the nonhuman reality (what Descartes characterized as res extensa) occupying the place of the object; (2) its natural attitude was dominating reality and 
even other human beings; hence, life was conceived of as a dominating adaptation of the environment to its own interests; (3) it attributed absolute infallibility to the evidence of internal perception; and (4) it represented self-control as an ethical path and therefore was marked by philosophical egocentrism.

Within this framework, in which "selfishness [...] constitutes the starting point and the foundation of bourgeois civilization" (Entralgo 1961, p. 216), sociability (i.e., relationality) played a secondary role. For the bourgeois person (that of the Anglo-Saxon liberalism of J.S. Mill, Locke, Hume and Adam Smith's capitalism), society is a "cold and distant mechanical relationship between individuals, primarily focused on their own self and radically alone; even more, vocationally alone, since for modern individualism sociability [is a] pure external and subordinate bond of rational and free atoms" (Entralgo 1961, p. 213).

It was undoubtedly twentieth-century Jewish thought that contributed the most to the development of relation as an anthropological category. A group of philosophers of Jewish origin, namely, Buber, Heschel, Jonas and Levinas, focused their reflection on the human person in the midst of the multiple attacks on the human being that marked the twentieth century, from capitalism to communist totalitarianism, including atrocities of nationalism such as Nazism. Thus, these philosophers developed a personalism that, supported by theological revelation, can be qualified as deeply relational. The Judeo-Christian God of the Bible and the Talmud is a personal God, and Adam, created in his image and likeness, is, in turn, a person because he is constituted in the relationship with another, with the Absolute.

The first part of Buber's book I and Thou is a treatise on relation as constitutive of the human being. With hardly any mediation, Buber asserts the existence of two basic words that "do not describe something that might exist independently of them [but] are spoken from the being" (Buber 1958, p. 3): I-Thou and I-It. Of the two, the first captures the totality of being. This is how Buber, from the first moment, introduces the category of relation into the person's being.

According to Buber, relation is the cause of both humanization and hominization. On the one hand, relation causes humanization in immediate and reciprocal encounters. It is immediate since "no system of ideas, no foreknowledge, and no fancy intervene between I and Thou [...] No aim, no lust, and no anticipation intervene between I and Thou" (Buber 1958, p. 11), and it is reciprocal since "My Thou affects me, as I affect it" (Buber 1958, p. 15). On the other hand, the relation causes hominization: "In the beginning is relation" (Buber 1958, p. 18). Buber then explains that in the "spiritual history of the primitive", "already in the original relational event he speaks the primary word I-Thou in a natural way [...] that is, before he has recognized himself as I" (Buber 1958, p. 22).

\section{Bioethical implications}

The anthropological turn introduced by Max Scheller and the Jewish thinkers of the twentieth century meant abandoning the ideal of the monadic individual and thus considering the idea of relationality to be constitutive of the human person. However, current medical ethics, largely developed at the "heart of individualistic autonomy" (Dove et al. 2017), have maintained solipsistic imaginary. When making health decisions, the ideal situation seems to be for the patient to decide only for him-/herself (Veltman and Piper 2014; Jennings 2016). The common representation of the patient is similar to that of the Cartesian cogito: a rational, self-interested, transparent entity for whom personal wishes and volition are fully conscious (Mackenzie and Stoljar 2000; Mackenzie 2014). The role of the doctor is reduced to providing neutral and complete information on the diagnostic and therapeutic possibilities so that the patient can decide among them (Entwistle et al. 2010; Walter and Ross 2014; Gómez-Vírseda et al. 2020). However, this situation has little to do with clinical reality.

Considering the anthropological dimension of relationality promotes a fairer explanation of real clinical practice. Patients are not isolated persons who make self-interested decisions based on presumed scientific rationality (Agich 1990; Ho 2008; Walter and Ross 2014). Similarly, there is no doctor-patient interaction in which the role of the latter is absolutely neutral. The relational environment, which involves family, friends and communities, inevitably conditions the patient who must make decisions. Moreover, this occurs in a specific cultural and social context (Ho 2008). For this reason, some ethicists demand that the doctor-patient dyadic scheme be abandoned and seek new ways to involve others in the decision-making process (Roest et al. 2019; Gómez-Vírseda et al. 2020).

COVID-19 may have eliminated the boundaries of an individualistic view of autonomy. During the pandemic, patients were not allowed to make self-interested decisions without considering social interests (Baum and Żok 2020). Likewise, the scarcity of resources has critically limited individual decision-making capacity, giving a decisive voice to the doctor who must allocate this or that resource. The insufficiency of the individualistic model and of the physician-patient approach that is centered exclusively on the patient's interests has therefore been confirmed (Berlinger et al. 2020). The need to broaden the scope and incorporate other actors, namely, family members, other patients, society, etc., into the dialogue has become increasingly evident.

\section{Existential phenomenology: relations in the entrails of being}

In Heidegger's existentialism, one can find the fifth incorporation of relation into philosophical reflection. 
According to Heidegger, Husserl's path did not lead to things themselves because he had not moved away from his own subjectivity and had not broken the subject-object dialectic of modernity. Husserl's mistake was to conceive of the being as a mere thing, a mere essence (Zubiri 1963, p. 262). Hence, Heidegger's proposal to "reach the things themselves" springs from the human being since the human being is the only one who can pose the question of Being and answer it: "This entity which each of us is himself and which includes inquiring as one of the possibilities of its Being, we shall denote by the term Dasein (Being-there)" (Heidegger 1962, p. 27). As a result of this capacity, it is said that the Dasein is a "being in the world". Therefore, the question of being must begin with the analysis of Dasein. A first approach to this question affirms that "the essence of this entity lies in its 'to be' [be relatively to]" (Heidegger 1962, p. 67). In other words, its existence, its way of being in the world, is open. It is an open being.

That being-in-the-world, moreover, is in-the-world, but not like any other being. In the world, the Dasein discovers other beings that one must know and dominate. These are the "beings at hand" that have categories and not existentials. Furthermore, in the world, there are other "beings at hand" that are Dasein as well. The relation with the other Dasein is different from that with other "beings at hand". The other Dasein are not before the eyes; one is also with them: "These entities are neither present-at-hand nor ready-to-hand; on the contrary, they are like the very Dasein which frees them, in that they are there too, and there with it" (Heidegger 1962, p. 154).

This concomitance (there with it) is constitutive of Dasein: "Their Being-in-themselves within-the-world is Dasein-with" (Heidegger 1962, p. 155), and "[T]his Dasein-with of the Others is disclosed within-the-world for a Dasein, and so too for those who are Dasein with us, only because Dasein in itself essentially Being-with" (Heidegger 1962, p. 156). This is the exact place of the category of relation in Heidegger's thought: the Dasein is a being in the world and an open being concomitant of other Dasein.

Such a relational understanding of the Dasein has implications in its concrete existence and in the way of living it: the Dasein, being-in-the-world-with-others, can benefit from these relations to better itself or not. If the latter is the case, the Dasein reaches a fallen state characterized by anonymity and mediocrity. Faced with this dilemma, the Dasein can have an authentic existence if it faces the anguish of being-towards-death and does not turn away but rather accepts its condition: the Dasein that lives an authentic existence embraces its true condition of humanity and places itself in the truth. This authenticity is a moral mandate for the Dasein.

\section{Bioethical implications}

Heidegger's philosophy deems relationality necessary to achieve an authentic existence, and authenticity is one of the classical conditions of autonomy proposed by Beauchamp and Childress (2019). The American authors develop three conditions for an action to be considered autonomous: first, the action should have an authentic intention; second, it should be free from external interference by health professionals, family members, or society; and third, the agent must be competent and sufficiently informed.

Heidegger's phenomenological-existential analysis poses the question of what an authentic intention is. In other words, when can we affirm that an action is in consonance with a person's authentic values and beliefs (Agich 1990)? The search for authenticity, according to Heidegger, can never enclose the human being but opens him/her to others.

In this sense, considering an ontological dimension of relationality may require adding a fourth condition to those proposed by Beauchamp and Childress (2019). In doing so, the principle of autonomy acquires a relational dimension that was present in the other three principles proposed by the American philosophers. Note that the principles of justice, beneficence and nonmaleficence did incorporate "the other" at their core, and they did have a relational dimension, while the principle of autonomy remained trapped in problematic individualism, at least in terms of its "mainstream interpretation" (Donchin 2001). In our opinion, much of the criticism of American principlism reflects this imbalance.

Furthermore, stressing the relational character of the bioethical subject facilitates dialogue with alternative moral traditions. For instance, European bioethicists frequently insist on the need to balance individual autonomy with other principles, such as solidarity, vulnerability and integrity (Rendtorff 2002; Gaille and Horn 2016). Greater integration of relationality into the ethical subject would promote a more fluid dialogue with European principlist proposals.

\section{Hermeneutic philosophy: relation as the foundation of identity}

Paul Ricoeur's hermeneutic thought represents the sixth way to incorporate the category of relation into philosophy. The French author, who can be situated in the same framework delineated by Heidegger and the philosophy of language, exists in the so-called hermeneutical circle.

The starting point is the Kantian affirmation of the phenomenon in the face of the noumenon. The object of knowledge, the phenomenon, is a construct of the thing itself together with the categories of knowledge. The subject is active in knowing and inevitably leaves his or her traces on these categories. This happens even in the "question of meaning", which Heidegger poses as the deepest level of 
being. At this point, he agrees with Dilthey, Scheleiermacher and the philosophy of language: language is the active way in which the knowing subject constructs the phenomenon, including meaning itself.

This is how Paul Ricoeur upholds the idea that time- - the other part of reality together with the being, as declared by Heidegger-is not immediately given to our knowledge but is constructed by language. Hence, he reaches the narrative, which is the way in which human beings incorporate the category of time into knowledge.

In his treatise on philosophical anthropology, Paul Ricoeur proposes the "hermeneutics of selfhood" as the way to address the problem of identity. Indeed, identity is the issue at stake in the human being when the narrative is integrated into self-knowledge. For Ricoeur, in the question "Who?" (Who is this? Who said that? Who are we?), one discovers the difference between the idem and the ipse (Ricoeur 2016, p. 222). The former relates to something that does not change, the latter to something "susceptible of unfolding a narrative course" (Ricoeur 2016, p. 224). In Ricoeur's words, "the identity of the ipse does not reduce to the substantial identity of an idem, in the sense of something unchanging, but combines a basic mutability. It is the mediating function of the narrative to hold together the anecdotal mutability of a life and the configuration of a story" (Ricoeur 2016, p. 225). Immediately following this, Ricoeur focuses on the study of ipseity, i.e., narrative identity, and addresses the topic of the incorporation of relation.

According to the French philosopher, Kant's Critique of Pure Reason places relation in the judgments that link what is enduring in the phenomenon with certain modes of its existence, i.e., with what changes. He categorically affirms, "[T] he notion of the interconnectedness of a life undercuts this categorization, which is valid only for the axioms applicable to physical nature" (Ricoeur 2016, p. 231).

In the identity problem, relation does not connect the substance (what endures) with the mutable but rather connects the mutable with the narrative plot. The time of the narrative plot is not something given or enduring (as Heidegger might affirm); rather, it is mutable. Thus, relation is a category that binds two mutable things: the who and the narrative. Ricoeur thus conceives of relation as the connection that constitutes identity.

\section{Bioethical implications}

Ricoeurian hermeneutics foregrounds the narrative constitution of personal identity. In other words, personal identity is not a static essence to be discovered but rather a dynamic construct to be elaborated. In this line, Levy (2011) distinguishes between two visions: the "self-discovery view" and the "self-creation view". In the self-discovery view, authenticity means being true to oneself and listening to an "inner voice" that all humans possess. In contrast, in the self-creation view, authenticity is an effort to create oneself as one wishes to be. The hermeneutic perspective fits better in the latter view, in which human beings build their identity in a continuous process of interaction with others.

In parallel, narrative ethics points out that personal identity involves a life story that takes place in cultural communities with shared traditions and a horizon of expectations (Ikonomidis and Singer 1999; Rigaux 2011; Siddiqui 2016). Continuity with one's own biography and community is important for a medical decision to be considered authentic and meaningful (Westlund 2009). In the dominant bioethical discourse, there is a tendency to conceptualize autonomy as a succession of isolated decisions, thereby losing the perspective of a continuous and relational process (Baumann 2008; Lindberg et al. 2014). In fact, decision making takes place in a diachronic and relational context, that is, in a history marked by relationships of trust and mutual knowledge (Marx et al. 2014). In this regard, promoting patients' autonomy requires helping them integrate health decisions into their own biography while seeking temporal coherence and the support of significant communities (Donchin 2001; Tonelli and Misak 2010).

Suffering from COVID-19 has too frequently meant a fracture in the biographical dimension of the patient. For emergency reasons, medical and public health criteria have prevailed over individual wishes, sometimes overlooking biographical aspects of the patient (Strang et al. 2020). In reaction, several bioethical voices have insistently demanded interpersonal closeness in the processes of illness, death and mourning (Berlinger et al. 2020; Valera et al. 2020). These are relational processes, and not being accompanied during them - and instead undergoing them in the solitude and anonymity of a hospital - may have caused deep wounds to patients and family members (Anderson-Shaw and Zar 2020; Wakam et al. 2020).

In short, we have considered the need to incorporate relationality into the very core of reality and human beings from the perspectives of six branches of twentieth-century philosophy. Having gained these insights, we have extracted some bioethical implications, focusing specifically on the principle of autonomy. By doing so, we aim to respond to the challenges to an individualistic vision of autonomy presented at the beginning of this paper (see Table 1).

\section{Conclusions}

The individualistic vision of the principle of respect for autonomy has been challenged both by recent bioethical literature and by the clinical reality of the COVID-19 pandemic. A response to this challenge points to a relational turn of autonomy. However, weak or causal accounts of 
Table 1 Summary of philosophical branches, their insights and their bioethical implications

\begin{tabular}{|c|c|c|c|}
\hline Historical trends & $\begin{array}{l}\text { Philosophical branches (Primary } \\
\text { sources) }\end{array}$ & Insights and learnings & Bioethical implications \\
\hline \multirow[t]{3}{*}{ The emergence of social sciences } & $\begin{array}{l}\text { Cultural Anthropology (E.B. } \\
\text { Tylor) }\end{array}$ & $\begin{array}{l}\text { The biocultural human being is in } \\
\text { relation to others }\end{array}$ & $\begin{array}{l}\text { Necessary cultural awareness in } \\
\text { bioethics }\end{array}$ \\
\hline & $\begin{array}{l}\text { Philosophy of Nature (A.N. } \\
\text { Whitehead) }\end{array}$ & $\begin{array}{l}\text { Everything is interconnected: a } \\
\text { cosmological perspective }\end{array}$ & $\begin{array}{l}\text { Medical ethics opened to global and } \\
\text { environmental ethics }\end{array}$ \\
\hline & $\begin{array}{l}\text { Discourse Ethics (J. Habermas, } \\
\text { K.O. Apel) }\end{array}$ & $\begin{array}{l}\text { Relation as a condition of univer- } \\
\text { sal morality }\end{array}$ & $\begin{array}{l}\text { Towards a shared decision-making } \\
\text { approach and procedures }\end{array}$ \\
\hline \multirow[t]{3}{*}{ The evolution of phenomenology } & $\begin{array}{l}\text { Philosophical Anthropology (M. } \\
\text { Scheler, M. Buber) }\end{array}$ & $\begin{array}{l}\text { Relationality in the human defini- } \\
\text { tion, beyond an individualistic } \\
\text { framework }\end{array}$ & $\begin{array}{l}\text { A relational understanding of deci- } \\
\text { sion making, beyond the doctor- } \\
\text { patient dyad }\end{array}$ \\
\hline & $\begin{array}{l}\text { Existential Phenomenology (M. } \\
\text { Heidegger) }\end{array}$ & $\begin{array}{l}\text { Authenticity definitely attained } \\
\text { through relations }\end{array}$ & $\begin{array}{l}\text { Respect for personal autonomy has } \\
\text { an inescapable relational dimen- } \\
\text { sion }\end{array}$ \\
\hline & Hermeneutics (P. Ricoeur) & $\begin{array}{l}\text { Relation in the search for personal } \\
\text { identity }\end{array}$ & $\begin{array}{l}\text { Narrative dimension of decision- } \\
\text { making processes: diachronic and } \\
\text { relational }\end{array}$ \\
\hline
\end{tabular}

relationality have caused relational autonomy to function as an "umbrella term" (Mackenzie and Stoljar 2000) with inadequate development at the theoretical and practical levels. To achieve a strong account of relationality, we have analyzed the way in which six philosophical branches successfully integrated relationality into their theoretical core throughout the twentieth century. From this historical analysis, we have extracted implications that can guide a strong account of relationality in bioethics.

On a theoretical level, the full incorporation of relationality into bioethics requires overcoming individualistic anthropology and, with it, transforming classical principlism. First, relational items are added to the conditions for an action to be considered autonomous. Second, elements of narrative and hermeneutics are incorporated into the search for authentic intentionality in decision making.

On a practical level, a relational account of autonomy aligns well with the development of SDM in bioethics. However, a strong vision of relationality requires that these dialogical proposals go beyond the doctor-patient dyad to incorporate ever wider circles in the dialogue. This development points towards global bioethical proposals to address health issues such as COVID-19, not only from a medical point of view but also by integrating economic, social, cultural and ecological perspectives. Complex problems require complex approaches, and relationality is embedded in the heart of reality.

Acknowledgements The authors want to thank Rodrigo López and Roberto Villasante for their help in the various steps of drafting the manuscript.

Author contributions Both authors contributed equally to the drafting of the manuscript.
Funding Nothing to declare.

Data availability Not applicable.

Code availability Not applicable.

\section{Declarations}

Conflict of interest The authors have no conflicts of interest to declare that are relevant to the content of this article.

\section{References}

Agencia Española de Medicamentos y Productos Sanitarios. 2020. Exceptional measures applicable to clinical trials to manage problems arising from the COVID-19 emergency. Madrid: Agencia Española de Medicamentos y Productos Sanitarios.

Agich, George J. 1990. Reassessing autonomy in long-term care. The Hastings Center Report 20: 12-17. https://doi.org/10.2307/35634 17.

Álvarez, Ángel. G. 1967. Tratado de metafísica: Ontología. Barcelona: Editorial Gredos.

Amengual, Gabriel. 2007. Antropología filosófica. Madrid: Biblioteca de Autores Cristianos.

Anderson-Shaw, Lisa K., and Fred A. Zar. 2020. COVID-19, moral conflict, distress, and dying alone. Journal of Bioethical Inquiry 17: 777-782. https://doi.org/10.1007/s11673-020-10040-9.

Arias, Maximino. 1989. La doctrina trinitaria de San Agustin. Teología y Vida 30: 249-270.

Aristotle. 1956. Metaphysics, 20th ed. Trans. John Warrington. London: JM Dent and Sons.

Augustine. 417/1956. Tratado de la santísima trinidad, V, 5, 6, 2nd ed. Madrid: Biblioteca de Autores Cristianos.

Baum, Ewa, and Agnieszka Żok. 2020. Assumptions of maximal individualism in the time of the COVID-19 pandemic: Ethical aspects. Society Register 4: 79-88. https://doi.org/10.14746/sr.2020.4.3.04. 
Baumann, Holger. 2008. Reconsidering relational autonomy. Personal autonomy for socially embedded and temporally extended selves. Analyse \& Kritik 30: 445-468. https://doi.org/10.1515/ auk-2008-0206.

Beauchamp, Tom L., and James F. Childress. 2019. Principles of biomedical ethics, 8th ed. New York: Oxford University Press.

Berlinger, Nancy, Mattew Wynia, Tia Powell, D. Micah Hester, Aimee Milliken, Rachel Fabi, Felicia Cohn, Laura K. GuidryGrimes, Jamie Carlin, Lori Bruce, Elizabeth J. Chuang, Grace Oei, Jean Abott, and Nancy P. Jenks. 2020. Ethical framework for health care institutions responding to novel coronavirus SARS-CoV-2 (COVID-19) guidelines for institutional ethics services responding to COVID-19. The Hastings Center. https:// www.thehastingscenter.org/wp-content/uploads/HastingsCe nterCovidFramework2020.pdf. Accessed 20 Mar 2020.

Betancourt, Joseph R. 2004. Cultural competence-Marginal or mainstream movement? New England Journal of Medicine 351: 953-955. https://doi.org/10.1056/nejmp048033.

Boladeras, Margarita. 1996. Comunicación, ética y política. Habermas y sus críticos. Madrid: Tecnos.

Buber, Martin. 1958. I and thou, 2nd ed. Trans. Ronald Gregor Smith. New York: Charles Scribner's Sons.

Calvo, Rafael A., Sebastian Deterding, and Richard M. Ryan. 2020. Health surveillance during COVID-19 pandemic. British Medical Journal 369: m1373. https://doi.org/10.1136/bmj.m1373.

Candib, Lucy M. 2002. Truth telling and advance planning at the end of life: Problems with autonomy in a multicultural world. Families, Systems, and Health 20: 213-228. https://doi.org/10. 1037/h0089471.

Childress, James F. 1990. The place of autonomy in bioethics. The Hastings Center Report 20: 12-17. https://doi.org/10.2307/ 3562967.

Clouser, K. Danner., and Berdnard Gert. 1990. A critique of principlism. Journal of Medicine and Philosophy 15: 219-236. https://doi.org/10.1093/jmp/15.2.219.

Collingwood, Robin G. 1945. The idea of nature. Oxford: Clarendon Press.

Coutts, Christopher, and Micah Hahn. 2015. Green infrastructure, ecosystem services, and human health. International Journal of Environmental Research and Public Health 12: 9768-9798. https://doi.org/10.3390/ijerph120809768.

Donchin, Anne. 2000. Autonomy and interdependence: Quandaries in genetic decision-making. In Relational autonomy: Feminist perspectives on autonomy, agency, and the social self, ed. Mackenzie Catriona and Natalie Stoljar, 236-258. New York: Oxford University Press.

Donchin, Anne. 2001. Understanding autonomy relationally: Toward a reconfiguration of bioethical principles. The Journal of Medicine and Philosophy 26: 365-386. https://doi.org/10.1076/jmep. 26.4.365.3012.

Dove, Edward S., Susan E. Kelly, Federica Lucivero, Mavis Machirori, Sandi Dheensa, and Barbara Prainsack. 2017. Beyond individualism: Is there a place for relational autonomy in clinical practice and research? Clinical Ethics 12: 150-165. https://doi. org/10.1177/1477750917704156.

Dworkin, Gerald. 1988. The theory and practice of autonomy. Cambridge: Cambridge University Press.

Elwyn, Glyn, Dominick Frosch, Richard Thomson, Natalie JosephWilliams, Amy Lloyd, Paul Kinnersley, Emma Cording, Dave Tomson, Carole Dodd, Stephen Rollnick, Adrian Edwards, and Michael Barry. 2012. Shared decision making: A model for clinical practice. Journal of General Internal Medicine 27: 1361-1367. https://doi.org/10.1007/s11606-012-2077-6.

Entralgo, Pedro L. 1961. Teoría y realidad del otro: El otro como otro yo. Nosotros, tú y yo, vol. 1. Madrid: Revista de Occidente.
Entwistle, Vikki A., Stacy M. Carter, Alan Cribb, and Kirsten McCaffery. 2010. Supporting patient autonomy: The importance of clinician-patient relationships. Journal of General Internal Medicine 25: 741-745. https://doi.org/10.1007/ s11606-010-1292-2.

European Medicines Agency. 2020. Guidance on the management of clinical trials during the COVID-19 (coronavirus) pandemic. London: EUSEM.

Ezcurra, Javier O. 1991. Teoría del proceso en AN Whitehead. Universitas Philosophica 9: 67-82.

Faden, Ruth R., and Tom L. Beauchamp. 1986. A history and theory of informed consent. New York: Oxford University Press.

Fox, Renée C. 2005. Cultural competence and the culture of medicine. New England Journal of Medicine 353: 1316-1319. https://doi. org/10.1056/nejmp058066.

Frosch, Dominick L., and Robert M. Kaplan. 1999. Shared decision making in clinical medicine: Past research and future directions. American Journal of Preventive Medicine 17: 285-294. https:// doi.org/10.1016/s0749-3797(99)00097-5.

Gaille, Marie, and Ruth Horn. 2016. The role of 'accompagnement' in the end-of-life debate in France: From solidarity to autonomy. Theoretical Medicine and Bioethics: Philosophy of Medical Research and Practice 37: 473-487. https://doi.org/10.1007/ s11017-016-9389-1.

Gilbar, Roy, and José Miola. 2015. One size fits all? On patient autonomy, medical decision-making, and the impact of culture. Medical Law Review 23: 375-399. https://doi.org/10.1093/medlaw/ fwu032.

Gómez-Vírseda, Carlos, Yves de Maeseneer, and Chris Gastmans. 2019. Relational autonomy: What does it mean and how is it used in end-of-life care? A systematic review of argument-based ethics literature. BMC Medical Ethics 20: 76. https://doi.org/10.1186/ s12910-019-0417-3.

Gómez-Vírseda, Carlos, Yves de Maeseneer, and Chris Gastmans. 2020. Relational autonomy in end-of-life care ethics: A contextualized approach to real-life complexities. BMC Medical Ethics 21: 1-14. https://doi.org/10.1186/s12910-020-00495-1.

Habermas, Jürgen. 1990. Moral consciousness and communicative action. Trans. Christian Lenhardt and Shierry Weber Nicholsen. Cambridge: Polity Press.

Heidegger, Martin. 1962. Being and time. Trans. John Macquarrie and Edward Robinson. New York: Harper and Row Publishers.

Heilbron, Johan. 2014. The social sciences as an emerging global field. Current Sociology 62: 685-703. https://doi.org/10.1177/00113 92113499739.

Ho, Anita. 2008. Relational autonomy or undue pressure? Family's role in medical decision-making. Scandinavian Journal of Caring Sciences 22: 128-135. https://doi.org/10.1111/j.1471-6712. 2007.00561.x.

Ikonomidis, Sharon, and Peter A. Singer. 1999. Autonomy, liberalism and advance care planning. Journal of Medical Ethics 25: 522-527. https://doi.org/10.1136/jme.25.6.522.

Jeffrey, David I. 2020. Relational ethical approaches to the COVID-19 pandemic. Journal of Medical Ethics 46: 495-498. https://doi.org/ 10.1136/medethics-2020-106264.

Jennings, Bruce. 2016. Reconceptualizing autonomy: A relational turn in bioethics. Hastings Center Report 46: 11-16. https://doi.org/ 10.1002/hast.544.

Kant, Immanuel. 1922. Critique of pure reason, 2nd ed. Trans. F. Max Müller. London: MacMillan Company.

Kon, Alexander A. 2010. The shared decision-making continuum. JAMA 304: 903-904. https://doi.org/10.1001/jama.2010.1208.

Lang, Kellie R., and D. Micah Hester. 2021. The centrality of relational autonomy and compassion fatigue in the COVID-19 era. The American Journal of Bioethics 21: 84-86. https://doi.org/10. 1080/15265161.2020.1850914. 
Légaré, France, and Holly O. Witteman. 2013. Shared decision making: Examining key elements and barriers to adoption into routine clinical practice. Health Affairs 32: 276-284. https://doi.org/10. 1377/hlthaff.2012.1078.

Levy, Neil. 2011. Enhancing authenticity. Journal of Applied Philosophy 28: 308-318. https://doi.org/10.1111/j.1468-5930.2011. 00532.x.

Lindberg, Catharina, Cecilia Fagerström, Bengt Sivberg, and Ania Willman. 2014. Concept analysis: Patient autonomy in a caring context. Journal of Advanced Nursing 70: 2208-2221. https://doi. org/10.1111/jan.12412.

Mackenzie, Catriona. 2014. Three dimensions of autonomy: A relational analysis. In Autonomy, oppression and gender, ed. Andrea Veltman and Mark Piper, 15-41. New York: Oxford University Press.

Mackenzie, Catriona, and Natalie Stoljar. 2000. Relational autonomy: Feminist perspectives on autonomy, agency, and the social self. New York: Oxford University Press.

Marx, Gabriella, Sonja O. Boakye, Antje Jung, and Friedemann Nauck. 2014. Trust and autonomy in end of life: Considering the interrelation between patients and their relatives. Current Opinion in Supportive and Palliative Care 8: 394-398. https://doi.org/10. 1097/spc.0000000000000096.

Marx, Reinhard C. 2016. Everything is connected": On the relevance of an integral understanding of reality in Laudato Si. Theological Studies 77: 295-307. https://doi.org/10.1177/0040563916635116.

McCullough, Laurence B. 2020. In response to COVID-19 pandemic physicians already know what to do. American Journal of Bioethics 20: 9-12. https://doi.org/10.1080/15265161.2020.1754100.

Mead, Erin L., Ardith Z. Doorenbos, Sara H. Javid, Emily A. Haozous, Lori A. Alvord, David R. Flum, and Arden M. Morris. 2013. Shared decision-making for cancer care among racial and ethnic minorities: A systematic review. American Journal of Public Health 103: e15-e29. https://doi.org/10.2105/AJPH.2013.301631.

Müller-Engelmann, Meike, Heidi Keller, Norbert Donner-Banzhoff, and Tanja Krones. 2011. Shared decision making in medicine: The influence of situational treatment factors. Patient Education and Counseling 82: 240-246. https://doi.org/10.1016/j.pec.2010. 04.028 .

O'Neill, Onora. 2002. Autonomy and trust in bioethics, 1st ed. Cambridge: Cambridge University Press.

Rendtorff, Jacob D. 2002. Basic ethical principles in European bioethics and biolaw: Autonomy, dignity, integrity and vulnerabilityTowards a foundation of bioethics and biolaw. Medicine, Health Care and Philosophy 5: 235-244. https://doi.org/10.1023/A: 1021132602330.

Ricoeur, Paul. 2016. Philosophical anthropology. Cambridge: Polity Press.

Rigaux, Natalie. 2011. Autonomy and dementia Part II: Autonomy and representation: A possible combination? Gériatrie Et Psychologie Neuropsychiatrie Du Viellissement 9: 203-210. https://doi.org/10. 1684/pnv.2011.0270.

Roest, Bernadette, Margo Trappenburg, and Carlo Leget. 2019. The involvement of family in the Dutch practice of euthanasia and physician assisted suicide: A systematic mixed studies review. BMC Medical Ethics 20: 23. https://doi.org/10.1186/ s12910-019-0361-2.

Rueda, Luis S. 2001. Movimientos filosóficos actuales. Madrid: Trotta. Sala, Javier S. M. 1999. Teoría de la cultura. Madrid: Síntesis.

Sherwin, Susan, and Katie Stockdale. 2017. Whither bioethics now? The promise of relational theory. International Journal of Feminist Approaches to Bioethics 10: 7-29. https://doi.org/10.3138/ ijfab.10.1.7.

Siddiqui, Shahla. 2016. Ethical challenges facing advance care planning. Asian Bioethics Review 8: 53-65. https://doi.org/10.1353/ asb.2016.0004
Spadaro, Alessandra. 2020. COVID-19: Testing the limits of human rights. European Journal of Risk Regulation 11: 317-325. https://doi.org/10.1017/err.2020.27.

Stacey, Dawn, France Légaré, Krystina Lewis, Michael J. Barry, Carol L. Bennett, Karen B. Eden, Margaret Holmes-Rovner, Hilary Llewellyn-Thomas, Anne Lyddiatt, Richard Thomson, and Lyndal Trevena. 2017. Decision aids for people facing health treatment or screening decisions. Cochrane Database of Systematic Reviews 4: CD001431. https://doi.org/10.1002/ 14651858.CD001431.pub5.

Stiggelbout, Anne M., Arwen H. Pieterse, and Johanna C. J. M. De Hae. 2015. Shared decision making: Concepts, evidence, and practice. Patient Education and Counseling 98: 1172-1179. https://doi.org/10.1016/j.pec.2015.06.022.

Stoljar, Natalie. 2018. Feminist perspectives on autonomy. In The Stanford encyclopedia of philosophy, ed. Edward N. Zalta. https://plato.stanford.edu/entries/feminism-autonomy. Accessed 27 Feb 2021.

Strang, Peter, Jonas Bergström, Lisa Martinsson, and Staffan Lundström. 2020. Dying from COVID-19: Loneliness, end-of-life discussions, and support for patients and their families in nursing homes and hospitals. A national register study. Journal of Pain and Symptom Management 60: e2-e13. https://doi.org/10. 1016/j.jpainsymman.2020.07.020.

Tatay, Jaime. 2020. Bioética global, ecoética y covid-19. In La humanidad puesta a prueba. Bioética y COVID-19, ed. R. Amo Usanos and F. Montalvo Jääskeläinen, 167-179. Madrid: Universidad Pontificia Comillas.

Thiebaut, Carlos L. 2000. La ética continental. In La filosofía hoy, ed. Javier M. Carpintier and Pedro C. Galán, 279-286. Barcelona: Crítica.

Tonelli, Mark R., and Cheryl J. Misak. 2010. Compromised autonomy and the seriously ill patient. Chest 137: 926-931. https:// doi.org/10.1378/chest.09-1574.

Traphagan, John W. 2013. Rethinking autonomy: A critique of principlism in biomedical ethics. New York: SUNY Press.

Tylor, Edward B. 1871. Primitive culture: Researches into the development of mythology, philosophy, religion, art and custom, vol. II. London: John Murray.

U.S. Department of Health and Human Services Food and Drug Administration. 2020. FDA guidance on conduct of clinical trials of medical products during COVID-19 public health emergency: Guidance for industry, investigators, and institutional review boards. https://www.fda.gov/media/136238/download. Accessed 27 Feb 2021.

Valera, Luca, María A. Carrasco, Rodrigo López, Paulina Ramos, Rommy von Bernhardi, Paula Bedregal, Alejandra Florenzano, Iván. Pérez, Patricia Olivares, Ivonne Vargas, Ximena González, Paulo López, Gloria Durán, Constanza Richards, and Ricardo Castro. 2020. Orientaciones éticas para la toma de decisiones médicas en el contexto de la pandemia de COVID-19 en Chile. Revista Médica de Chile 148: 393-398. https://doi.org/10.4067/ s0034-98872020000300393.

Valverde, Carlos. 2009. Prelecciones de metafísica fundamental. Madrid: Biblioteca de Autores Cristianos.

van der Graaf, Rieke, Marie A. Hoogerwerf, and Martine C. de Vries. 2020. The ethics of deferred consent in times of pandemics. Nature Medicine 26: 1328-1330. https://doi.org/10.1038/ s41591-020-0999-9.

Veltman, Andrea, and Mark Piper. 2014. Autonomy, oppression, and gender. New York: Oxford University Press.

Wakam, Glenn K., John R. Montgomery, Ben E. Biesterveld, and Craig S. Brown. 2020. Not dying alone-Modern compassionate care in the COVID-19 pandemic. New England Journal of Medicine 382: e88. https://doi.org/10.1056/NEJMp2007781. 
Walter, Jennifer K., and Lainie F. Ross. 2014. Relational autonomy: Moving beyond the limits of isolated individualism. Pediatrics 133: S16-S23. https://doi.org/10.1542/peds.2013-3608d.

Westlund, Andrea C. 2009. Rethinking relational autonomy. Hypatia 24: 26-49. https://doi.org/10.1111/j.1527-2001.2009.01056.x.

Whitehead, Alfred N. 1938. Modes of thought. New York: Macmillan.

Whitehead, Alfred N. 1964. The concept of nature. Cambridge: Cambridge University Press.

Whitehead, Alfred N. 1985. Process and reality. New York: The Free Press.

WHO. 2017. One health. Geneva: World Health Organization.

Zinsstag, Jakob, Esther Schelling, Lisa Crump, Maxine Whittaker, Marcel Tanner, and Craig Stephen. 2020. One health: The theory and practice of integrated health approaches, 2nd ed. Wallingford: $\mathrm{CAB}$ International.

Zubiri, Xavier. 1963. Cinco lecciones de filosofía. Madrid: Sociedad de Estudios y Publicaciones.

Publisher's Note Springer Nature remains neutral with regard to jurisdictional claims in published maps and institutional affiliations. 